\title{
Patient Education in General Practice
}

\author{
P.F.M. Verhaak and J.T. van Busschbach \\ Niveh Nederlands Instituut, voor Onderzoek van de Eerstelijnsgezondheidszorg, Utrecht \\ (The Netherlands)
}

(Received June 4th, 1987)

(Accepted November 19th, 1987)

\begin{abstract}
To study health education as provided by physicians, 550 videotaped doctor-patient interactions have been observed. Attention has been paid to the amount of information given about cause of illness, diagnosis, examination, purpose of treatment and prognosis. Though in most cases some information is given about some of these aspects, a real explanation is a far more unusual plenomenon. Instructions about the use of medication and home remedies are given in $70 \%$ till $80 \%$ of the cases. In $7 \%$ of the cases, the doctor imparted basic knowledge about illness, while in $15 \%$ of the cases life-style was discussed. These last two activities, going beyond the particular complaints that the patients presented, are called patient education.

After describing the amount of information, instruction, and education given, the relationship between the interaction during the consultation and the information communicated is studied. Interest and concern for the patient, as shown by the doctor has a positive relationship with information giving. However, it did not increase patient's tendency to ask questions. Patient centered behaviour of the doctor did not show a relationship with information giving nor with question asking. In fact, the best predictor of both the amount of information given in a consultation as well as of the degree of questioning was the duration of the consultation.
\end{abstract}

Key words: patient education, federal practitioner, doctor-patient communication, observation research.

\section{Introduction}

Health Education, in its most recognizable form, is directed at the healthy and it is concerned with the maintenance of health. It is, however, equally important, if not more so, for the sick to be properly informed of the nature of their illness, of the reasons for a particular course of treatment and of what they are supposed to do and what they are to refrain from doing. For a combination of moral, legal, psychological and professional reasons, it is regarded as essential that each patient is adequately informed about the nature of his illness and the diagnostic and other procedures required $[1,2]$. Furthermore, if the patient is responsible for his own treatment, i.e. for the taking of medicines or for a particular regime, he must be given intelligible instruction. 
It should be remembered that health care professionals are also in the position to teach patients about their bodies and give advice about appropriate life styles [3].

Accordingly, our topic may be called patient information, instruction, and education. Patient information is concerned with the complaint as it is presented: all information about cause, nature, prognosis, necessary examination, and treatment is covered by this term. Patient instruction comes into the picture when a treatment (medication, home remedy, a referral too) is prescribed. Patient education has a more general goal: it deals with life style and concerns advice that goes beyond the particular complaints that are presented at the time. Information and instruction are obligatory with each new complaint, as a necessary part of treatment; patient education may be a part of each consultation, but the content is dependent on the circumstances of the patient, his history, etc. The topic has received particular attention in the hospital setting, which is not surprising, as surgery and diagnostic intervention in hospitals are dramatic events. In many countries such intervention cannot take place without the informed consent of the patient. General Practice should meet the same requirements. The cases seen there and the consequences of treatment may be less serious in many respects, but to achieve patient compliance and cooperation, it is necessary for a patient visiting his doctor to be properly informed and receive adequate instruction. Garrity gives an overview of the existing literature in this respect [4].

One cannot consider patient information, instruction and education, in isolation, separate from the total process of communicative interchange and the practitioner-patient relationship.

Doctor-patient communication has been typified by Waitzkin as a patient, asking few questions and a doctor, volunteering little information [5]. He quotes Platt and McMath [6] who describe a doctor's 'high control style': asking many questions, keeping tight control over the interaction, preventing the patient from speaking at any length, and ending up with the question: 'are there any questions?' (cf. Byrne and Long's concept of doctor-centred behaviour [7]). It has been proved that information given within this context is less useful than given in a context where the patient is encouraged to be active [8,9].

Another feature of the doctor-patient communication which is considered as a necessary condition for the fruitful reception of information is the socioemotional atmosphere of the consultation [1]. If a patient meets with understanding and concern on the part of the doctor, he will be more likely to recall information and to comply with the instructions given [10]. Patientcentered behaviour and an understanding attitude on the part of the general practitioner may also encourage the patient to ask questions. Given the fact that many general practitioners say that they give information if, and only if, the patient asks about it [11], questions from the patient may be considered as an important outcome of a patient-centered conversation style.

At present there is little empirical data available on the degree to which general practitioners pay attention to patient information, instruction, and education. A great deal of research has been done on doctor-patient 
communication including information exchange, but this has always been done in rather abstract terms [9,12-14]. McClellan reviews a number of studies, regarding patient education but he considers the poor definition of the concept as a major methodological limitation, accounting for a suspected overreporting of the time doctors spend on patient education activity [15].

Furthermore, most of the studies reviewed by McClellan, bear upon assessments by practitioners themselves. Waitzkin [5] also measured the proportion of time devoted to information giving, with trained observers and a standardized definition and found a considerable lower rate. However, Waitzkin also failed to specify the type of information.

In our present investigation, we will give an impression of the extent of patient information, -instruction, and -education in general practice, and relate this to the interaction during the consultation. The content of the communication is measured by observation; trained observers, using welldefined concrete observation categories watched 550 videotaped consultations. This obviated the methodological shortcomings, mentioned above. We will take into account the relationship between the amount of information, actually given and the communication characteristics of the consultation in order to investigate whether patient-centered behaviour or an understanding attitude is related to the amount of information.

Finally, we will consider the question as to whether such characteristics enable the patient to put forward more questions. The questions posed by this investigation were:

- How much information, instruction, and education is actually given when the complaints mentioned are presented?

- Is there a relationship between the general atmosphere during the consultation and the amount of information communicated?

- Is there a relationship between the general atmosphere during the consultation and the number of questions, asked by the patient?

\section{Method}

In our investigations we have assessed the sort and the amount of information and instruction given in concrete terms. We did this by observing 550 videotaped doctor-patient encounters. Videotapes are extremely useful in assessing the way a doctor gives his patients information, and his behavior in other respects. Recording is generally rather unobtrusive. The material can be studied very carefully and listened to repeatedly; it can also be preserved and used again later for other purposes. This is what we did with the consultations from which the results presented derive. About 2,700 consultations were made over a period of years for other research purposes.

These consultations came from 59 practices. These practices were involved in several more or less random investigations, for which video recordings were made. The 59 practices are not representative in all respects of Dutch general practice (there are more health centres in our sample that there are in The Netherlands and the practices are not evenly distributed geographically) and 
the GP's tend to have a slightly more positive attitude toward a patient-centred approach and postgraduate training, especially on doctor-patient communication than Dutch doctors in general. However, with regard to age, sex, and type of complaint, the patients are comparable with average patients.

Doctors and patients were informed that recordings were being made, but not that patient information was the object of study. In fact, even the researcher was not aware of this at the time, because it was decided to use the recordings to study this topic a number of years later. From this data base we selected 550 consultations with the following characteristics.

All consultations on complaints or illness selected were new cases and had not been presented to the doctor before: our research is thus on new complaints. This has been done to make sure that the necessary information, instruction, or education had not been given on an earlier occasion. Secondly, we selected a narrow range of complaints, i.e. complaints of the ear, the skin and the common cold. We chose these three groups because they are complaints about which patients can be given information on medication and they can be frequently treated at home.

The consultations were observed by trained observers. At first they underwent training together. Then 30 consultations were observed by each observer separately. This yielded interobserver reliabilities varying from $\mathbf{0 . 5 3}$ to 0.80 . Afterwards (about 6 months later), one observer repeated the observations. Intraobserver reliability varied from 0.55 to 0.75 . A few advantages of the method used have already been mentioned: the possibility of accurate observation of well-defined concepts, unobtrusive measures because of the doctor's unawareness of the purpose of the recording and the possibility of studying a large and uniform sample. As a major disadvantage we mention the impossibility of gathering additional information about the patient's reactions to the consultation. We consider a large scale description as worthwhile as an effect study on a less reliable base.

\section{Information}

The amount of information given in each consultation was assessed for five different aspects of illness and treatment: cause of illness, diagnosis, prognosis, examination that takes place during the consultation and purpose of prescribed treatment.

An assessment was given for each section; if there was no treatment or examination, the assessment of that part was of course inapplicable. If the information was restricted to labelling the illness, for example telling a patient with earache that it was a case of 'otitis media', it was called superficial. When the doctor explained what 'otitis media' meant, the most positive assessment (explanation) was given.

How much information did our patients receive? See the following table (Table I): GPs seldom give an explanation of complaints. If they do so, it hardly ever concerns the examination or prognosis. Is information often given in answer to patients questions? The following table shows the answer is no (Table II). 
TABLE I

AMOUNT OF INFORMATION GIVEN DURING 550 CONSULTATIONS

\begin{tabular}{|c|c|c|c|c|}
\hline \multirow[t]{2}{*}{ Subject } & \multirow{2}{*}{$\begin{array}{l}N \\
\text { of cases }\end{array}$} & \multirow{2}{*}{$\begin{array}{l}\text { No } \\
\text { information } \\
(\%)\end{array}$} & \multicolumn{2}{|c|}{ Information given? } \\
\hline & & & $\begin{array}{l}\text { Superficial } \\
(\%)\end{array}$ & $\begin{array}{l}\text { Explanatory } \\
(\%)\end{array}$ \\
\hline Examination & 489 & 35 & 63 & 2 \\
\hline Diagnosis & 527 & 21 & 63 & 16 \\
\hline Cause of illness & 522 & 56 & 28 & 16 \\
\hline Prognosis & 515 & 62 & 34 & 4 \\
\hline Purpose of treatment & 596 & 36 & 45 & 19 \\
\hline
\end{tabular}

In only $25 \%$ of the consultations questions are put forward and only $34 \%$ of these questions result in full explanation. Two interesting phenomena are illustrated here. The patient is a rather passive partner in the relationship and, even when he is active, there is a good chance that he will only receive superficial information.

We observed rather large differences between the general practitioners regarding information giving. It is possible to estimate these differences of those 25 GPs who contributed 10 consultations or more to the research sample. From a one-way analysis of variance we concluded that information about diagnosis, cause, prognosis, and purpose of treatment had been given in significantly different degree by these GPs (Table III).

Information about examination appeared to be as dependent upon the nature of the complaint as upon the GP concerned. From these results we might infer that some doctors have more or less a habit to discuss a possible cause of illness, a prognosis, or a purpose of treatment, while others do this rather as an exception than as a rule.

TABLE II

PATIENTS' QUESTIONS AND INFORMATION GIVING

\begin{tabular}{llrrrr}
\hline Subject & Question? & Nof cases & \multicolumn{1}{c}{ No } & \multicolumn{2}{c}{ Information given? } \\
\cline { 4 - 6 } & & & & \multicolumn{1}{c}{ Superficial } & Explanatory \\
\hline Examination & Yes & 12 & $6(50 \%)$ & $5(42 \%)$ & $1(8 \%)$ \\
& No & 477 & $166(35 \%)$ & $302(63 \%)$ & $9(2 \%)$ \\
Diagnosis & Yes & 64 & $2(3 \%)$ & $47(73 \%)$ & $15(23 \%)$ \\
& No & 463 & $109(24 \%)$ & $285(61 \%)$ & $69(15 \%)$ \\
Cause & Yes & 61 & $9(15 \%)$ & $34(56 \%)$ & $18(30 \%)$ \\
& No & 461 & $281(61 \%)$ & $117(25 \%)$ & $63(14 \%)$ \\
Prognosis & Yes & 23 & $2(9 \%)$ & $20(87 \%)$ & $1(4 \%)$ \\
& No & 492 & $317(64 \%)$ & $156(32 \%)$ & $19(4 \%)$ \\
Purpose of & Yes & 30 & $8(27 \%)$ & $12(40 \%)$ & $10(33 \%)$ \\
treatment & No & 566 & $209(37 \%)$ & $254(45 \%)$ & $103(18 \%)$ \\
\hline
\end{tabular}


TABLE III

DIFFERENCES BETWEEN 25 GPS IN INFORMATION GIVING

\begin{tabular}{lllll}
\hline Subject & $\begin{array}{l}\text { Mean proportion of } \\
\text { consultations in } \\
\text { which somehow in- } \\
\text { formation had been } \\
\text { given by the GP } \\
\text { lowest in range }\end{array}$ & $\begin{array}{l}\text { Mean proportion of } \\
\text { consultations in } \\
\text { which somehow in- } \\
\text { formation had been } \\
\text { given by the GP } \\
\text { highest in range }\end{array}$ & $F$ & $P$ \\
& $50 \%$ & $100 \%$ & & \\
\hline Diagnosis & $7 \%$ & $82 \%$ & 2.175 & $P<0.01$ \\
Cause & $10 \%$ & $75 \%$ & 2.141 & $P<0.01$ \\
Prognosis & $30 \%$ & $100 \%$ & 2.684 & $P<0.05$ \\
Purpose of treatment & & & & $P<0.01$ \\
\hline
\end{tabular}

\section{Instruction}

Instruction giving was measured by assessing the number of times an instruction was given when medicines were prescribed, when the patient was advised to use a home remedy, or when the patient was referred (to a specialist or for further diagnostic investigation). Instruction about medicine, could concern the name of the medicine, the possible side-effects, the period during which the medicine had to be taken, the dose, the number of times or days the medicine had to be taken, and the time of the day the patient ought to take the medicine.

Instruction about referral is regarded as important because many patients are not aware of the administrative procedures nor of the requirements for many diagnostic investigations, such as fasting beforehand, for example.

Table IV makes clear that instruction about medication, and moreover, home remedies is given rather often. Instruction about medication is mostly about the way the medicine should be taken (dose, frequency, time, period); in a minority of cases information about its nature (possible side-effects, name) is given.

The elaborateness of instruction, measured by counting the number of

\section{TABLE IV}

FREQUENCY OF INSTRUCTION GIVING

\begin{tabular}{lll}
\hline Instruction on & $\begin{array}{l}\text { Nof times a treatment } \\
\text { is prescribed }\end{array}$ & $\begin{array}{l}\text { Proportion of cases } \\
\text { where instruction } \\
\text { was given }\end{array}$ \\
\hline Medication & 395 & $68 \%$ \\
Home remedy & 55 & $83 \%$ \\
Referral & 25 & $55 \%$ \\
Diagnostic investigation & 69 & $26 \%$ \\
\hline
\end{tabular}


relevant aspects as mentioned above, varies between GPs: as an average 2.67 aspects were mentioned, but the GP highest in range mentioned 3.55 aspects, the GP lowest in range $1.00(F=2,00, P<0.01)$.

When a patient is referred to a specialist or to a diagnostic agency, instruction is given less frequently. As was the case with informing the patient about the complaint, patients seldom ask for instructions. For example: $10 \%$ of all instructions given about medication were the result of patient's questions.

\section{Education}

Education was measured in terms of the following items:

- Does the GP impart basic knowledge about illness?

- Are topics concerning life style discussed (e.g. smoking or drinking behavior, physical training, sport, eating habits)

The first item was answered positively in 7\% of the cases. In 5 out of $\mathbf{5 5 0}$ consultations, we observed the doctor using written information for this purpose; $35 \%$ of this type of education was a result of patients questions. Life style was discussed slightly more frequently. Smoking, eating habits, and the advice to the patient to reduce stress were observed in a number of cases, generally, however, this was rather non-committal. These topics occurred in about $25 \%$ of the common cold cases, but in the skin- and earcases only $4 \%$ and $7 \%$, respectively. The latter do not seem to provide a good opportunity for the discussion of general life style features.

In looking over these results, one does not get the impression that information and education are very important issues as far as doctors or, surprisingly enough, patients are concerned. At least in so far as the latter demonstrate such a concern by asking the doctor what they want to know. The whole topic of education was observed too infrequently to take into consideration the possible differences between GPs in this respect.

\section{Information giving and the atmosphere in the consultingroom}

As we have suggested in the presentation of the research questions, we looked also at the conversational context, within which patient information etc. took place. The factors examined in the consultation were:

- attention, interest, and concern of the doctor. Important factors when one wants to establish a good relationship with the patient $[16,17,18]$

- the amount of time the doctor is able to spend on the patient [19]

- patient-centred behaviour on the part of the doctor. This last is demonstrated by the doctor giving the patient the opportunity to bring forward his own views and proposals about his symptoms and their treatment [7].

We assumed that these features were related to patient information, etc. and should possibly facilitate the patients' inclination to ask questions. To test this assumption we looked at one detail of the information giving process more closely. This was the degree to which full explanation of the complaint was 
given (on either diagnosis, prognosis, or cause). Full explanation of each variable in itself is observed too infrequently to be fruitful. Full explanation of one of the three aspects mentioned, refers to a single concept, namely explanation of the nature of the complaint and is observed to a sufficient degree. The following graphs (Figs. 1-3) show the relationship between consultation features (interest and concern of the doctor, time, patient-centred behaviour) on the one hand, and the proportion of full explanation and the proportion of patients questions on the other hand. (For details about operationalization and measurement see Ref. 20.)

In consultations where the doctor shows interest and concern for the patient and in consultations that last a relatively long time, more real information is given (Pearsons' $R=0.22$ resp. $0.30 ; P<0.01$ ). Whether the doctor lets the patient tell his own story or not appears to count less; (Pearsons' $R=-0.01$; NS). The atmosphere in the consulting room, however, does not seem to affect the number of questions asked by the patient (Pearsons' $R=-0.01$; NS). The only feature of the consultation that seems to matter in this respect is the duration of the consultation (Pearsons' $R=0.13,0.05<P<0.10$ ).

\section{Conclusions}

What conclusions can be drawn? First, the information and education given by general practitioners is restricted, as was also reported by McClellan [15] and Waitzkin [5]. It has hitherto played a minor part when compared with the curative tasks a doctor performs. This is a remarkable result in several

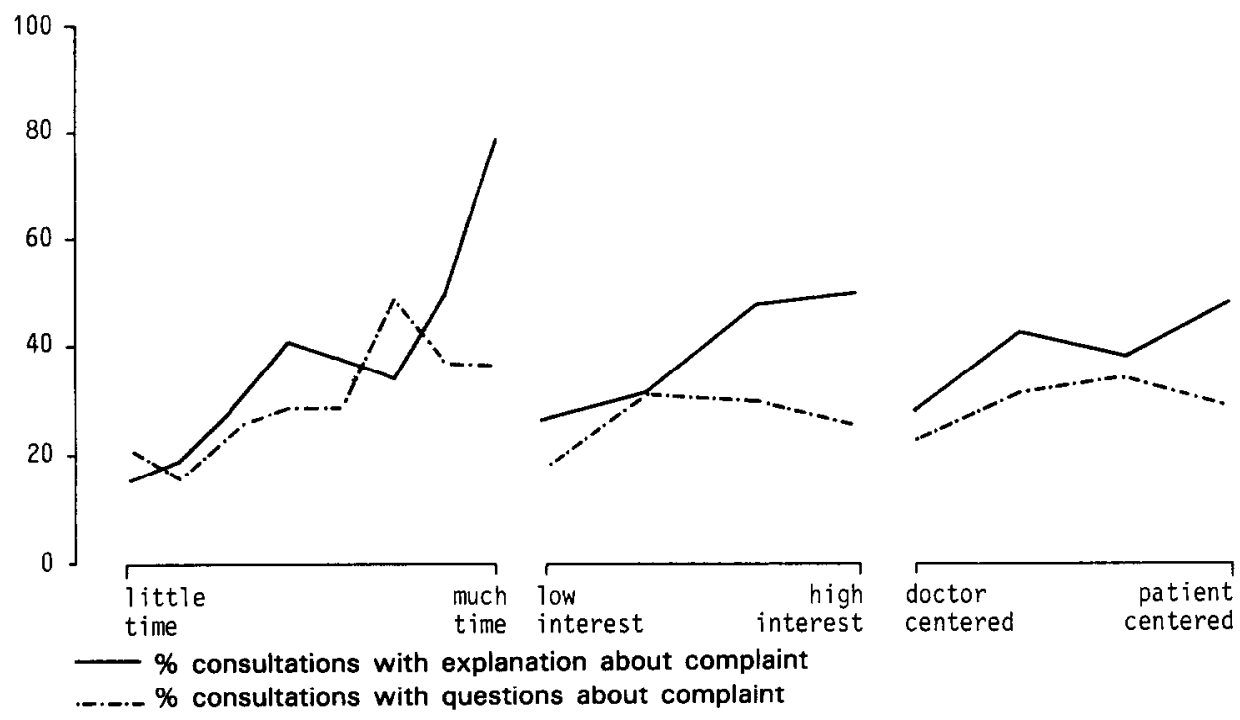

Figs. 1-3. Fig. 1. Relationship between duration of consultation and amount of information giving and patient questions. Fig. 2. Relationship between doctor's interest and amount of information giving and patient's questions. Fig. S. Relationship between doctor/patient-centred behaviour and amount of information giving and patient's questions. 
respects: when questioned about it, GPs give the impression that informing patients about the nature of their illness is a natural part of the doctor's job. Furthermore, since the World Health Organization accepted the slogan 'Health for all in the year 2000' health promotion and health education have gained in importance at the expense of a more curative attitude. Little of this can be seen in our results: health education plays a rather minor and secondary role in the work of general practitioners. One very seldom witnesses a doctor handing over copies of the wide range of carefully designed health education material.

When we take a close look at the objectives formulated by Fass et al. [3] in order to teach residents patient education skills, we can conclude that many of them are not achieved in an ordinary general practice at present. Fass et al. state: 'Residents will inform the patient of any findings', 'Residents will explain the treatment plan', 'Residents will encourage and respond to questions from the patient'. A short look at Tables I - IV suffices to show that this is not part of a GP's standard repertoire yet.

Equally remarkable are the results about the conditions that are supposed to facilitate the processes of information and education. Fass et al. stress the importance of a patient-centred attitude, and the use of open-ended questions, to encourage the patient to ask questions. Neither patient-centred behaviour, nor the interest and concern shown by the doctor seem to have the supposed facilitating effect.

In addition to this, we refer to Roter's pledge for a partnership model of client provider relations [21] in order to establish solid ground for health education. This model is approximated by our concept of patient-centred behaviour, where doctor and patient discuss the various diagnostic and therapeutic possibilities together, and where the condition that 'the client (is provided) with a basis for effective participation in sound decision making' (Roter, Ref. 28) is fulfilled. As we saw (Fig. 3), patient-centred behaviour is not a guarantee of more information nor of active patient behaviour. Perhaps it is too mechanistic a point of view to believe that there should be a direct relationship between doctor's behaviour (not taking into account the doctor-patient relationship, history, expectancies) and patient's reactions. It may be necessary to consider the style of a doctor as a 'whole', his basic attitude. At the end of this discussion we shall consider that point again.

To complete our summary of results, one of the few clear relationships between informing and educating the patient and common features of the consultation is that of the effect of the duration of the consultation. When a doctor allows his patients more time, the chance of a full explanation is increased, as is the likelihood that the patient will ask the questions he wants to.

Finally, the patients wishes are unclear. It would be very useful to know more about patients assessment of the value of information and about its effects on his future life style and illness behaviour.

But it also appeared that there were major differences between general practitioners, in all respects measured. From this we might conclude that it is, in principle possible for the GP to provide information. 
These results show that the GP should not wait for the patient to ask questions, because even an inviting attitude does not increase the amount of questioning. Given the fact that GP's are often not aware of the patients' information needs, a thorough assessment of these needs at the start of the consultation might be worthwhile [5,22]. This will take time in the short term, but may save a lot of time and trouble in the future. To use such an approach, the general practitioner must deal with his patients on a basis of equality; if he adopts a paternalistic point of view it is not possible for him to assume that he does not know what the patient knows (or need to know, according to the GP). The general practitioner must have a favourable attitude towards prevention also: he must believe in the significance of the time invested. These are parts of a more basic attitude, that has to do with a change from 'cure' to 'care', a change that might gradually be included by vocational and postgraduate training.

Within medical schools this has been a disputed issue the past 10 years in The Netherlands and the United Kingdom [23,24]. There is a difference in interest between the education of clinical competence and communication skills; until now most attention has been gone to the former, at the expense of the latter. However, there are signs now that things are changing (resulting, in The Netherlands for instance, in a 2- or 3-year general practice training instead of 1 year after several years hospital training). There may be hope for the future of patient information.

\section{References}

1 Dimatteo MT, DiNicola DD. Achieving Patient Compliance. New York: Pergamon Press, 1982.

2 Ley P. Patient's understanding and recall in clinical communication failure. In: Pendleton D, Hasler J eds. Doctor-Patient Communication. London: Academic Press, 1983.

3 Fass M, Vahldieck LM, Meyer DL. Teaching Patient Education Skills. Department of Family Medicine and Practice. University of Wisconsin, Madison, WI, 1983.

4 Garrity TF. Medical compliance and the clinician-patient relationship: a review. 1981; $15 \mathrm{E}: 215$ $-222$.

5 Waitzkin H. Doctor-patient communication. Clinical Implications of Social Scientific Research. J. Am Med Assoc 1984; 252: 2441-2446.

6 Platt FW, McMath JC. Clinical Hypocompetence: the interview. Ann Inter Med 1979; $91: 898$ $-902$.

7 Byrne PS, Long BEL. Doctors Talking to Patients. London, Her Majesty's Stationary Office, 1976.

8 Schulman BA. Active patient orientation and outcomes in hypertensive treatment. Med Care 1979; $17: 267-280$.

9 Roter DL. Patient participation in the patient-provider interaction: the effects of patient question asking on the quality of interaction, satisfaction and compliance. Health Education Monogr 1977; 5: $281-315$.

10 Francis PHN, Korsch BM, Morris MJ. Gaps in doctor-patient communication. New Engl J Med 1969; 280: 535- 540 .

11 Spronk VRA, Warmenhoven NE. Patient education in general practice: opinions of general practitioners. Patient Educ Couns 1983; 5: 68-75.

12 Bain DJG. Patient knowledge and the content of the consultation in general practice. Med Educ 1977; 11: 347 - 356.

13 Davis MS. Physiological, psychological and demographic factors in patient compliance with doctor's orders. Med Care 1968; 6: 115-122. 
14 Pendleton DA, Bochner S. The communication of medical information in general practice consultations as a function of patients' social class. Soc Sci Med 1980; 14A:669-673.

15 McClellan W. The physician and patient education: a review. Patient Educ Couns 1986; 8: 151 163.

16 Ben-Sira $Z$. The function of the professional's affective behaviour in client satisfaction: a revised approach to social interaction theory. J Health Soc Behav 1976; 17:3-11.

17 Ben-Sira Z. Affective and instrumental components in the physician-patient relationship: an additional dimension of interaction theory. J Health Soc Behav 1980;21: 170-180.

18 Ben-Sira Z. Stress potential and esotericity of health problems: the significance of the physician's affective behavior. Med Care 1982; 20: 414-424.

19 Bain DJG. The relationship between time and clinical management in family practice. J Fam Pract 1979b; 8: 745-753.

20 Verhaak PFM. Variations in the diagnosis of psychosocial disorders: a general practice observation study. Soc Sci Med 1986; 23: 595-604.

21 Roter D. An Exploration of health education's responsibility for a partnership model of clientprovides relations. Patient Educ Couns 1987; 9:25-31.

22 Kindelan K, Kent G. Patients' preferences for information. J R Coll Gen Pract 1986; 36: 461 463.

23 Wakeford R. Communication skills training. In: Pendleton D, Hasler J eds. Doctor-Patient Communication. London: Academic Press, 1983.

24 Hasler J. The consultation and postgraduate general practice training. In: Pendleton D, Hasler JJ eds. Doctor-Patient Communication. London: Academic Press, 1983. 